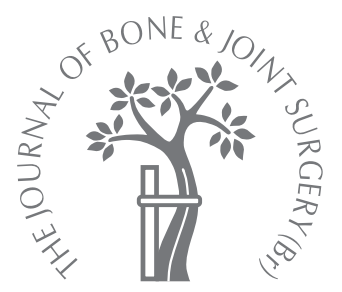

\title{
Inverted V-shaped high tibial osteotomy compared with closing-wedge high tibial osteotomy for osteoarthritis of the knee
}

\author{
TEN-YEAR FOLLOW-UP RESULT
}

\begin{abstract}
Y. Aoki,
K. Yasuda,

S. Mikami,

H. Ohmoto,

T. Majima,

A. Minami
\end{abstract}

From Hokkaido

University School of

Medicine, Sapporo,

Japan

\begin{abstract}
We compared the results ten years after an inverted V-shaped high tibial osteotomy with those of a historical series of conventional closing-wedge osteotomies. The closing-wedge series consisted of 56 knees in 51 patients with a mean follow-up of 11 years (10 to 15). The inverted V-shaped osteotomy was evaluated in $\mathbf{4 8}$ knees in $\mathbf{4 3}$ patients at a mean follow-up of 14 years (10 to 19). All the patients were scored using the Japanese Orthopaedic Association rating scale for osteoarthritis of the knee and radiological assessment.

The pre-operative grade of osteoarthritis was similar in both groups. Post-operatively, the knee function score was graded as satisfactory in $63 \%$ (35) of the closing-wedge group but in $89 \%(43)$ of the inverted V-shaped osteotomy group. Post-operative radiological examination showed that delayed union and loss of correction occurred more often after a closing-wedge osteotomy than after an inverted V-shaped procedure.

Our study suggests that the inverted $V$-shaped osteotomy may offer more dependable long-term results than traditional closing-wedge osteotomy.
\end{abstract}

High tibial osteotomy is an effective treatment for unicompartmental osteoarthritis of the knee. Many studies have reported favourable results at follow-up of ten years. ${ }^{1-10}$ However, recent studies have shown that this procedure cannot prevent progression of radiological degenerative changes ${ }^{11}$ and others have indicated that there is a progressive deterioration after ten years. ${ }^{5,7,9,12-17}$ Factors influencing the long-term results after high tibial osteotomy, such as age, pre-operative deformity of the knee, the extent of degeneration of the articular cartilage and the angle of correction after operation, have been studied over the last two decades. ${ }^{1,4,6,10-13,18-26}$ Aglietti et al ${ }^{1}$ stated that undercorrected knees had a high incidence of progression of both further varus angulation and arthropathy. They also reported that the angle of correction was the most significant factor influencing the long-term results, ${ }^{1,11}$ with overcorrection recommended for high tibial osteotomy. ${ }^{1,11,14}$ It has been advised that the femorotibial angle of the knee should be corrected to approximately $168^{\circ} .{ }^{23}$ It is necessary for the corrected femorotibial angle which is obtained at operation to be maintained throughout the post-operative period. Closing-wedge osteotomy has been commonly used, ${ }^{1-6,9,10,12-}$ 15,19-22,27 but some studies have described a high incidence of delayed union and recurrent varus. ${ }^{3,10,13,28}$ In 1973 , Levy et al ${ }^{29}$ described an inverted V-shaped osteotomy (the V procedure). No studies have been carried out to evaluate this procedure in comparison with a standard closing-wedge osteotomy.

Our aim was to compare the results after high tibial osteotomy performed as a closingwedge with those obtained from a $\mathrm{V}$ procedure at a minimum follow-up of ten years.

\section{Patients and Methods}

We performed a closing-wedge high tibial osteotomy on 86 knees in 78 patients between 1971 and 1977, and a V procedure on 77 knees in 72 patients between 1981 and 1990. The results of the first outcome examination, undertaken in 1990 for patients who had undergone a closing-wedge high tibial osteotomy were compared with those performed in 2002 and 2004 for patients who underwent the $\mathrm{V}$ procedure. Patients who had a high tibial osteotomy between 1978 and 1980 were excluded from the study because we carried out a number of different procedures for a small number of patients during this time.

At the first follow-up examination of the patients with a closing-wedge it was found that 12 had died and 14 were lost to follow-up. One was excluded because of a severe comminuted fracture of the femoral condyle. This left 56 knees in 51 patients with a mean follow-up of 11 years ( 10 to 15 ). There were 12 men (13 


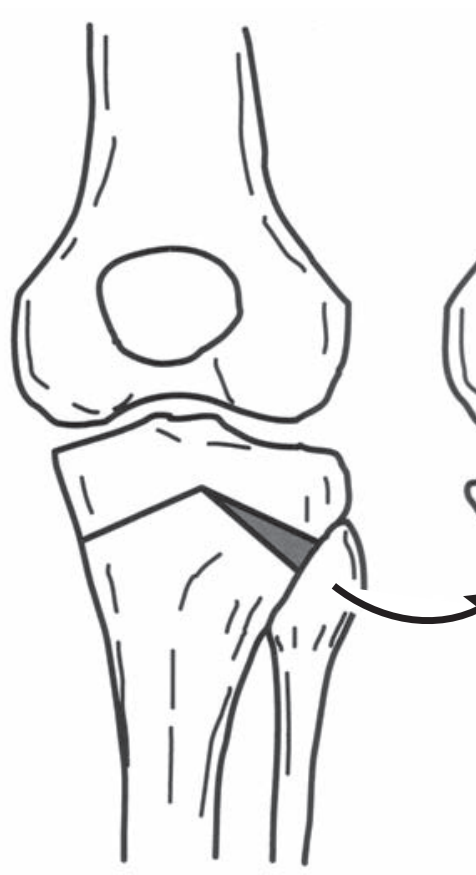

a

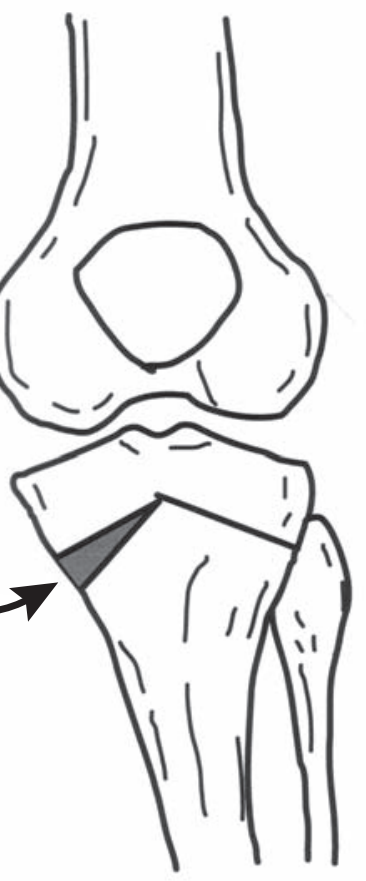

b
Fig. 1

Diagrams of an inverted $\mathrm{V}$-shaped osteotomy showing a) a wedge of cancellous bone resected from the tibia beneath the lateral plateau in the shape of an inverted ' $V$ ' and b) valgus correction and grafting of the resected wedged bone block into the triangular gap created beneath the medial plateau.

knees) and 39 women (43 knees) with a mean age at the time of operation of 59.8 years (47 to 72 ).

When the patients with the $\mathrm{V}$ procedure were examined 14 had died and 11 were lost to follow-up. In addition, four were excluded because of poor general health or knee injury. Therefore, 48 knees in 43 patients were reviewed at a mean follow-up of 14 years (10 to 19). There were 11 men (13 knees) and 32 women ( 35 knees) with a mean age at the time of operation of 59.5 years (43 to 75 ).

Operative techniques. Before operation, the required angle of correction was determined from a single leg-stance fulllength anteroposterior radiograph. The intention was to obtain a correction so that the mechanical axis would pass through the centre of the lateral tibial plateau. The femorotibial angle under this condition was between $165^{\circ}$ and $168^{\circ}$.

For the closing-wedge osteotomy, the proximal tibiofibular joint was either released or the head of the fibula was excised. Under fluoroscopic guidance, a Steinmann pin (AO/ASIF, Switzerland) $5 \mathrm{~mm}$ in diameter was inserted percutaneously into the tibia $1 \mathrm{~cm}$ distal to and parallel to the articular surface. Approximately $5 \mathrm{~cm}$ distal to the first pin, another was inserted into the tibial diaphysis so that the angle created between the two pins corresponded to the required wedge. A wedged osteotomy was carried out between the two pins using a power saw or an osteotome, removing the bone fragment created. The surfaces of the osteotomy were adjusted until the pins were parallel, after which the two pins were secured together by an external fixation device.

For the $\mathrm{V}$ procedure, Levy's technique was modified ${ }^{29}$ (Fig. 1). Approximately $1 \mathrm{~cm}$ to $1.5 \mathrm{~cm}$ of the central section of the fibula was resected using a small oscillating saw. Two Steinmann pins were inserted into the tibia as in the closing-wedge osteotomy. The osteotomy, in the shape of an inverted ' $\mathrm{V}$ ' of the planned correction angle, was carried out using a broad osteotome or a power saw under direct vision. The apex of the $\mathrm{V}$ was proximal to the tibial tuberosity under the patellar tendon. A wedge of cancellous bone was resected from the tibia beneath the lateral plateau. This was followed by an osteotomy beneath the medial plateau, and valgus correction was performed so that the two Steinmann pins became parallel and were then secured using external fixators. The resected bone block was placed into the triangular space which had been created beneath the medial plateau.

In both types of osteotomy the patients were advised to start active mobilisation of the knee after operation. Generally, partial weight-bearing was started six weeks after surgery. The external fixator was removed and full weightbearing was allowed once union was observed radiologically.

Clinical and radiological evaluation. The patients were evaluated using the Japanese Orthopaedic Association score (JOA score) $)^{23}$ (Table I) for osteoarthritis of the knee. This is used as the standard knee function scale in Japan. Based on our previous study, ${ }^{23}$ the results were graded as good for total JOA scores of 85 to 100 points, fair for 70 to 84 and poor for 69 or less. Patients who had undergone total knee replacement (TKR) after high tibial osteotomy were graded as poor.

For radiological evaluation, the femorotibial angle was measured and the stage of osteoarthritis was evaluated using the Hokkaido University stage grading system, ${ }^{23}$ from the anteroposterior radiographs of the knee in the single-leg stance position (Table II). Radiological evaluation was performed before, one year after operation and at the final review.

The length of time until full weight-bearing was allowed, the time of removal of the external fixator, changes in the tibial plateau angle during the first-year after operation, and the incidence of delayed union, where delayed union was defined as absence of union at four months after operation, were also compared.

Statistical analysis. This was performed using Student's unpaired $t$-test and the chi-squared test. A p-value $<0.05$ was considered to be statistically significant.

\section{Results}

The mean pre-operative JOA score was 53.2 (35 to 65) in the closing-wedge osteotomy series and 57.6 (35 to 70 ) in the $\mathrm{V}$ procedure group. 
Table I. Criteria for evaluation of osteoarthritis of the knee according to the Japanese Orthopaedic Association ${ }^{23}$

\begin{tabular}{|c|c|c|}
\hline Domain & Points & \\
\hline Pain on walking & Right & Left \\
\hline $\begin{array}{l}\text { Ability to walk } 1 \mathrm{~km} \text { or more usually without pain, or only } \\
\text { occasionally mild pain }\end{array}$ & 30 & 30 \\
\hline Ability to walk $1 \mathrm{~km}$ or more regardless of pain & 25 & 25 \\
\hline Ability to walk $500 \mathrm{~m}$ or more, but less than $1 \mathrm{~km}$ & 20 & 20 \\
\hline Ability to walk 100 m or more, but less than 500 m & 15 & 15 \\
\hline Ability to walk indoors or nearby, but less than $100 \mathrm{~m}$ & 10 & 10 \\
\hline Inability to walk & 5 & 5 \\
\hline Inability to stand & 0 & 0 \\
\hline \multicolumn{3}{|l|}{ Pain on ascending or descending stairs } \\
\hline No pain & 25 & 25 \\
\hline Pain relieved by using handrails & 20 & 20 \\
\hline Pain with handrails, but no pain with step-by-step ambulation & 15 & 15 \\
\hline Pain with step-by-step ambulation: relieved by using handrails & 10 & 10 \\
\hline Pain even with step-by-step ambulation and handrail use & 5 & 5 \\
\hline Inability to ascend or descend due to pain & 0 & 0 \\
\hline \multicolumn{3}{|l|}{ Range of movement } \\
\hline Ability to squat & 35 & 35 \\
\hline Ability to sit sideways or cross-legged sitting & 30 & 30 \\
\hline Flexion or arc of movement of $110^{\circ}$ or more & 25 & 25 \\
\hline Flexion or arc of movement of $75^{\circ}$ or more & 20 & 20 \\
\hline Flexion or arc of movement of $35^{\circ}$ or more & 10 & 10 \\
\hline $\begin{array}{l}\text { Flexion or arc of movement less than } 35^{\circ} \text { including ankylosis or } \\
\text { severe flexion contracture }\end{array}$ & 0 & 0 \\
\hline \multicolumn{3}{|l|}{ Joint effusion } \\
\hline No effusion, no swelling & 10 & 10 \\
\hline Occasional aspiration required & 5 & 5 \\
\hline Frequent aspiration required & 0 & 0 \\
\hline Total score & 100 & 100 \\
\hline
\end{tabular}

Table II. Radiological stage of osteoarthritis according to the Hokkaido University grading system ${ }^{23}$

\begin{tabular}{ll}
\hline Stage & Radiological findings \\
\hline I & Bony spur only \\
II & Narrowing of joint space (less than $1 / 2$ normal joint space) \\
III & Narrowing of joint space (more than $1 / 2$ normal joint space) \\
IV & Obliteration of joint space or minor bone erosion (less than $1 \mathrm{~cm}$ ) \\
V & Major bone erosion (more than $1 \mathrm{~cm}$ ) or subluxation
\end{tabular}

The mean pre-operative standing femorotibial angle was $185.4^{\circ}\left(180^{\circ}\right.$ to $\left.198^{\circ}\right)$ for the closing-wedge osteotomy group and $183.4^{\circ}\left(178^{\circ}\right.$ to $\left.196^{\circ}\right)$ in the $\mathrm{V}$ procedure group. Pre-operatively, according to the Hokkaido University grading system, the osteoarthritis was stage II in 14 knees $(25 \%)$, stage III in 31 knees (55\%), and stage IV in 11 knees $(20 \%)$ in the closing-wedge group, and stage II in 10 knees $(21 \%)$, stage III in 30 knees $(62 \%)$, and stage IV in eight knees $(17 \%)$ in the $\mathrm{V}$ procedure group. Using the chisquared test, there was no significant difference in the stage of osteoarthritis between the two groups before operation $(\mathrm{p}=0.76)$.

At the time of follow-up, TKR had been performed in two knees in the closing-wedge group and in four in the $\mathrm{V}$ procedure group.
In the remaining patients the mean JOA score improved from 53.2 (35 to 65) before operation to 74.4 (50 to 95) at the final follow-up in the closing-wedge group and from 57.6 (35 to 70 ) to 85.2 (55 to 100 ) in the $\mathrm{V}$ procedure group (Table III). The difference was significant in both groups using Student's $t$-test $(\mathrm{p}=0.0000014)$. The functional gradings of the JOA scores are presented in Table III. At the final follow-up, the results were graded as good in 10 $(18 \%)$, fair in $25(45 \%)$ and poor in $21(37 \%)$ in the closing-wedge group. In the $\mathrm{V}$ procedure group, the results were good in $27(56 \%)$, fair in $12(25 \%)$ and poor in 9 $(19 \%)$ (Table III). In the closing-wedge group there were fewer good results at the final review.

The radiological results are presented in Table IV. The mean femorotibial angle was significantly less in the $\mathrm{V}$ procedure group at the final review. At one year there had been a greater loss of correction in the closing-wedge group, but this did not reach statistical significance. There was no significant difference in the radiological stage of osteoarthritis between the two groups at the final followup.

The mean time to full weight-bearing post-operatively was 91.7 days ( 40 to 145 ) in the closing-wedge group and 71.9 days (35 to 110 ) in the $\mathrm{V}$ procedure group (Student's $t$-test, $\mathrm{p}=0.015)$. 
Table III. Comparison of clinical results between closing-wedge osteotomy and inverted V-shape osteotomy

\begin{tabular}{|c|c|c|c|}
\hline & Closing-wedge osteotomy & V procedure & p-value \\
\hline Number of knees & 56 & 48 & \\
\hline Mean (range) follow-up period (yrs) & 11 (10 to 15$)$ & 14 (10 to 19$)$ & \\
\hline \multicolumn{4}{|l|}{ Mean (range) $\mathrm{JOA}^{*}$ score } \\
\hline Pre-operative & 53.2 (35 to 65$)$ & 57.6 (35 to 70$)$ & $0.052^{\dagger}$ \\
\hline Final follow-up & $74.4(50$ to 95$)$ & $85.2(55$ to 100$)$ & $<0.001^{\dagger}$ \\
\hline \multicolumn{4}{|l|}{ Mean (range) range of movement $\left({ }^{\circ}\right)$} \\
\hline Extension & $-2.5(-8$ to 0$)$ & $-3.5(-8$ to 0$)$ & $0.261^{\dagger}$ \\
\hline Flexion & $126.9(95$ to 140$)$ & $127.3(100$ to 140$)$ & $0.815^{\dagger}$ \\
\hline \multicolumn{4}{|l|}{ Knee function (\%) } \\
\hline Good & 18 & 56 & \\
\hline Fair & 45 & 25 & \\
\hline Poor & 37 & 19 & $<0.001^{\ddagger}$ \\
\hline
\end{tabular}

Table IV. Comparison of the radiological results between closing-wedge osteotomy and inverted V-shape osteotomy

\begin{tabular}{lcccc}
\hline Results $^{*}$ & \multicolumn{2}{c}{ Closing-wedge osteotomy } & V procedure & p-value \\
\hline Number of knees & 56 & 48 & \\
Mean (range) FTA $\left(^{\circ}\right)$ & 170.6 (163 to 183) & 166.8 (157 to 176) & $<0.001^{\dagger}$ \\
Mean (range) change of FTA at & $1.3 \quad(-5$ to 12) & 0.2 (-5 to 5) & $0.032^{\dagger}$ \\
one-year post-operatively & & & & \\
\hline *FTA, femorotibial angle & & & & \\
†Student's $t$-test & & &
\end{tabular}

Delayed union was observed in $13(23 \%)$ knees in the closing-wedge group, but in only three $(6 \%)$ in the $\mathrm{V}$ procedure group. There was a significant difference between the two groups (chi-squared test, $\mathrm{p}=0.016$ ). Peroneal nerve palsy was observed in two knees in the closing-wedge group and in one in the $\mathrm{V}$ procedure group. Superficial infection at the site of insertion of a pin occurred in one knee in the closing-wedge group and in two in the $\mathrm{V}$ procedure group.

\section{Discussion}

We compared the long-term results of closing-wedge osteotomy with those after using a modified inverted $\mathrm{V}$ high tibial osteotomy. Good and fair results of knee function were found more often in the $\mathrm{V}$ procedure group. In the radiological evaluation, the mean femorotibial angle for the $\mathrm{V}$ procedure group at the final follow-up was significantly less than that with the closing-wedge osteotomy. The change in the tibial plateau angle at one year showed a greater tendency towards recurrent varus in the closingwedge series as well as a greater frequency of delayed union. The difference in the femorotibial angle at the final follow-up between the two procedures resulted from the change in tibial plateau angle found at the review at one year.

With closing-wedge osteotomies Insall et $\mathrm{al}^{19}$ reported satisfactory results in $37 \%$ of patients at a follow-up of more than nine years. Aglietti et al ${ }^{1}$ described excellent and good results in $64 \%$ after at least ten years and Rudan and Simurda ${ }^{10}$ had good and excellent results in $70 \%$ of 20 patients followed up for longer than ten years. Ivarsson et $\mathrm{al}^{20}$ noted acceptable results in $60 \%$ after 11 years. In our study the results were good and fair in $63 \%$ at a mean of 11 years and are comparable with other series.

However, in the inverted V-shape osteotomy group, good and fair results occurred in $81 \%$ of the patients. The preoperative condition of the knees treated by the two methods was similar. The most likely explanation for the difference between the two groups is better maintainence of correction at one year and at final follow-up in the $\mathrm{V}$ procedure group. In our study, the duration until removal of the external fixator did not differ between the two groups but in the closing-wedge group, the tibial plateau angle was often $3^{\circ}$ or more of varus immediately after the removal of the fixator. This suggests that bony union occurred earlier in the $\mathrm{V}$ procedure group. Closing-wedge high tibial osteotomy is an excellent operative technique with a long history, ${ }^{4,8,20,24,30}$ but must achieve close approximation after correction, otherwise delayed union may occur. ${ }^{13}$

In the $\mathrm{V}$ procedure bony union may occur more readily because the surface area of resected bone is about half that needed for a closing-wedge osteotomy. The medial gap is filled with bone graft and less periosteal dissection of the posterior tibia is required than for a closing-wedge osteotomy.

Several authors have emphasised the importance of adequate correction and maintenance of valgus alignment. ${ }^{1,11,12,14,18,21,26,29}$ In our study, it was recognised that the optimal range of the angle of correction was $164^{\circ}$ to 
$168^{\circ}$ and strict attention was given to obtaining this in both groups. It was obtained more frequently in the $\mathrm{V}$ procedure group than in the closing-wedge group since bony union occurred earlier in the $\mathrm{V}$ procedure group making retention of the optimal correction angle more likely.

Several authors have reported a correlation between recurrence of varus and progression of osteoarthritis. ${ }^{3-}$ $5,10,14,16,21$ We found that post-operative loss of correction was observed less frequently after the $\mathrm{V}$ procedure even though full weight-bearing was initiated significantly earlier than after closing-wedge osteotomy.

Total knee replacement after high tibial osteotomy may pose problems with lateral deviation of the proximal tibia and difficulty in managing the patella during operation due to patella baja. ${ }^{17}$ The $\mathrm{V}$ procedure should minimise these difficulties.

A weakness of our study is its reliance on a historical control and a lack of random allocation. Therefore the outcome between the two groups cannot be attributed to a difference in the two procedures with any degree of certainty. Also, the loss to follow-up was high, being slightly worse in the $\mathrm{V}$ procedure group, which alone might have accounted for the difference between the groups.

In order to obtain good long-term results of high tibial osteotomy, the acquisition and maintenance of a strict angle of correction are important. Any osteotomy should be performed with consideration of the possibility of a subsequent TKR. Acknowledging the shortcomings of our study, the results suggest that the inverted V-shaped high tibial osteotomy can maintain the optimal correction angle with lasting long-term results.

No benefits in any form have been received or will be received from a commercial party related directly or indirectly to the subject of this article.

\section{References}

1. Aglietti P, Rinonapoli E, Stringa G, Taviani A. Tibial osteotomy for the varus osteoarthritic knee. Clin Orthop 1983;176:239-51.

2. Jackson JP, Waugh W. Tibial osteotomy for osteoarthritis of the knee. J Bone Joint Surg [Br] 1961;43-B:746-51.

3. Rudan JF, Simurda MA. Valgus high tibial osteotomy: a long-term follow-up study. Clin Orthop 1991;268:157-60.

4. Stuart MJ, Grace JN, IIstrup DM, et al. Late recurrence of varus deformity after proximal tibial osteotomy. Clin Orthop 1990;260:61-5

5. Majima T, Yasuda K, Katsuragi R, Kaneda K. Progression of joint arthrosis 10 to 15 years after high tibial osteotomy. Clin Orthop 2000;381:177-84.

6. Berman AT, Bosacco SJ, Kirschner S, Avolio A. Factors influencing long-term results in high tibial osteotomy. Clin Orthop 1987;272:192-8.
7. Rinonapoli E, Mancini GB, Corvaglia A, Musiello S. Tibial osteotomy for varus gonarthrosis: a 10- to 21-year followup study. Clin Orthop 1998;353:185-93.

8. Ahlberg A, Scham S, Unander-Scharin L. Osteotomy in degenerative and rheumatoid arthritis of the knee joint. Acta Orthop Scand 1968;39:379-86.

9. Nagel A, Insall JN, Scuderi GR. Proximal tibial osteotomy: a subjective outcome study. J Bone Joint Surg [Am]1996;78-A:1353-8.

10. Rudan JF, Simurda MA. High tibial osteotomy: a prospective clinical and roentgenographic review. Clin Orthop 1990;255:251-6.

11. Aglietti P. High tibial valgus osteotomy for medial gonarthrosis: a 10- to 21 -year study. J Knee Surg 2003;16:21-6.

12. Hernigou PH, Medevielle D, Debeyre J, Goutallier D. Proximal tibial osteotomy for osteoarthritis with varus deformity: a ten to thirteen-year follow-up study. J Bone Joint Surg [Am] 1987;69-A:332-54.

13. Koshimo T, Tsuchiya K. The effect of high tibial osteotomy on osteoarthritis of the knee. Int Orthop 1979;3:37-45.

14. Nguyen C, Rudan J, Simurda MA, Cooke TDV. High tibial osteotomy compared with high tibial and Maquet procedures in medial and patellofemoral compartment osteoarthritis. Clin Orthop 1989;245:179-87.

15. Sprenger TR, Doerzbacher JF. Tibial osteotomy for the treatment of varus gonarthrosis: survival and failure analysis to twenty-two years. J Bone Joint Surg [Am] 2003:85-A:469-74.

16. Katz KM, Hungerford DS, Krackow KA, Lennox DW. Results of total knee arthroplasty after failed proximal tibial osteotomy for osteoarthritis. J Bone Joint Surg [Am] 1987;69-A:225-33.

17. Edwards RB 3rd, Seeherman HJ, Bogdanske JJ, et al. Percutaneous injection of recombinant human bone morphogenetic protein-2 in a calcium phosphate paste accelerates healing of a canine tibial osteotomy. J Bone Joint Surg [Am] 2004;86-A: 1425-38.

18. Coventry MB. Upper tibial osteotomy for gonaruthrosis: the evolution of the operation in the last 18 years and long term results. Orthop Clin North Am 1979;10:191-210.

19. Insall JN, Joseph DM, Msika C. High tibial osteotomy for varus gonarthrosis: a long-term follow-up study. J Bone Joint Surg [Am] 1984;66-A:1040-8.

20. Ivarsson I, Myrnerts R, Gillquist J. High tibial osteotomy for medial osteoarthritis of the knee. J Bone Joint Surg [Br] 1990;72-B:238-44.

21. Coventry MB. Osteotomy of the upper portion of the tibia for degenerative arthritis of the knee: a preliminary report. J Bone Joint Surg [Am] 1965;47-A:984-90.

22. Matthews LS, Goldstein SA, Malvitz TA, Katz BP, Kaufer H. Proximal tibial osteotomy: factors that influence the duration of satisfactory function. Clin Orthop 1988:229:193-200.

23. Yasuda K, Majima T, Tsuchida T, Kaneda K. A ten to 15-year follow-up observation of high tibial osteotomy in medial compartment osteoarthritis. Clin Orthop 1992; 282:186-95.

24. Coventry MB, Ilstrup DM, Wallrichs SL. Proximal tibial osteotomy: a critical longterm study of eighty-seven cases. J Bone Joint Surg [Am] 1993;75-A:196-201.

25. Vanionpaa S, Laike E, Kirves $\mathbf{P}$, Tjusanen P. Tibial osteotomy for osteoarthritis of the knee: a five to ten-year follow-up study. J Bone Joint Surg [Am] 1981;63-A: 938-46.

26. Tjornstrand BAE, Egund N, Hagstedt BV. High tibial osteotomy: a seven-year clinical and radiographic follow-up. Clin Orthop 1981;160:124-36.

27. Windsor RE, Insall JN, Vince KG. Technical consideration of total knee arthroplasty after proximal tibial osteotomy. J Bone Joint Surg [Am]1986;70-A:547-55.

28. Kettelkamp DB, Wenger DR, Chao EYS, Thompson C. Results of proximal tibial osteotomy: the effects of tibiofemoral angle, stance-phase flexion-extension, and medial-plateau force. J Bone Joint Surg [Am] 1976;58-A:952-60.

29. Levy M, Pauker M, Lotem M, Seelenfreund M, Fried A. High tibial osteotomy: a follow-up study and disruption of a modified technic. Clin Orthop 1973;93:274-7.

30. Coventry MB. Osteotomy about the knee for degenerative and rheumtoid arthritis. J Bone Joint Surg [Am] 1973;55-A:23-48. 